CLINICAL ETHICS

\title{
How physicians face ethical difficulties: a qualitative analysis
}

\author{
S A Hurst, S C Hull, G DuVal, M Danis
}

See end of article for authors' affiliations .....................

Correspondence to: $S$ Hurst, MD, Bioethics Research and Teaching Unit, Villa Thury 8/CMU, Rue Michel Serv 11,1211 Genève 4, Switzerland; samia.hurst@medecine. unige.ch

Received 16 July 2003 In revised form

15 October 2003

Accepted for publication

21 October 2003
J Med Ethics 2005;31:7-14. doi: 10.1136/jme.2003.005835

Background: Physicians face ethical difficulties daily, yet they seek ethics consultation infrequently. To date, no systematic data have been collected on the strategies they use to resolve such difficulties when they do so without the help of ethics consultation. Thus, our understanding of ethical decision making in day to day medical practice is poor. We report findings from the qualitative analysis of 310 ethically difficult situations described to us by physicians who encountered them in their practice. When facing such situations, the physicians sought to avoid conflict, obtain assistance, and protect the integrity of their conscience and reputation, as well as the integrity of the group of people who participated in the decisions. These goals could conflict with each other, or with ethical goals, in problematic ways. Being aware of these potentially conflicting goals may help physicians to resolve ethical difficulties more effectively. This awareness should also contribute to informing the practice of ethics consultation.

Objective: To identify strategies used by physicians in dealing with ethical difficulties in their practice.

Design, setting, and participants: National survey of internists, oncologists, and intensive care specialists by computer assisted telephone interviews $(n=344$, response rate $=64 \%)$. As part of this survey, we asked physicians to tell us about a recent ethical dilemma they had encountered in their medical practice. Transcripts of their open-ended responses were analysed using coding and analytical elements of the grounded theory approach.

Main measurements: Strategies and approaches reported by respondents as part of their account of a recent ethical difficulty they had encountered in their practice.

Results: When faced with ethical difficulties, the physicians avoided conflict and looked for assistance, which contributed to protecting, or attempting to protect, the integrity of their conscience and reputation, as well as the integrity of the group of people who participated in the decisions. These efforts sometimes reinforced ethical goals, such as following patients' wishes or their best interests, but they sometimes competed with them. The goals of avoiding conflict, obtaining assistance, and protecting the respondent's integrity and that of the group of decision makers could also compete with each other.

Conclusion: In resolving ethical difficulties in medical practice, internists entertained competing goals that they did not always successfully achieve. Additionally, the means employed were not always the most likely to achieve those aims. Understanding these aspects of ethical decision making in medical practice is important both for physicians themselves as they struggle with ethical difficulties and for the ethics consultants who wish to help them in this process.
P hysicians frequently encounter ethical difficulties. ${ }^{12}$ How do they resolve them? Ethics committees and consultation services are increasingly common in US hospitals, but most ethically difficult situations are not referred to them. Despite this, most research regarding the resolution of ethical difficulties in clinical practice has focused on the experience of ethics committees and consultation services. ${ }^{3-8}$ There has been no systematic, empirical examination of the values or the strategies actually employed by physicians to deal with the ethically problematic situations they face without help from ethics committees or consultants.

Moral reasoning and the moral development of health care providers has been studied using standardised tools. ${ }^{9-13}$ However, the association between moral reasoning and actual or intended action does not seem to be strong. ${ }^{14} 15$ This suggests that situational features not usually included in the scope of the studies, such as time constraints or interprofessional relations, may greatly influence the way in which ethical decision making actually takes place. Such situational features have not been subject to analysis, since studies have mostly used responses to hypothetical or otherwise standardised cases. ${ }^{16-18}$ This approach requires prior selection of those elements of a case that are deemed to be relevant and there is thus an inherent risk of disregarding elements that would have been deemed relevant by the decision makers in real situations. The study of real cases brought by the respondents themselves, including their own account of what they actually did, is therefore important in exploring the way ethical difficulties play out in practice.

We conducted a survey to explore the experiences of US internists regarding the ethical difficulties they encountered in their practice and their perception of ethics support services. Other data from this survey have been reported elsewhere. ${ }^{19}$ We present the findings from a qualitative analysis of open-ended questions designed to explore physicians' strategies and goals in dealing with ethical difficulties. Our purpose here is to describe these strategies and goals. By making them explicit we aim to help to inform the process of ethical decision making in clinical practice for both physicians and clinical ethics consultants. It should be clear that the data would not permit judgements of individual decisions as right or wrong, and that this is not the purpose here. 


\section{METHODS \\ Sample}

The participants were general internists, oncologists, and intensive care physicians, identified by random sampling from the American Medical Association Master List of Physicians and Medical Students for Mailing Purposes, which provides a comprehensive list of physicians practicing in the USA and is not limited to members of the American Medical Association. These specialties were chosen to capture physicians who are active in the primary care setting, as well as those providing highly technological care. US general internists receive 3 years of training in the specialty of internal medicine. The oncologists and intensive care specialists included in this study also have internal medicine training, with an additional 2 years of fellowship training in oncology or critical care medicine respectively. Since the purpose was to explore an aspect of clinical experience, physicians were eligible to participate if they reported practicing medicine for at least 1 year prior to the survey, and spending at least $20 \%$ of their time on direct patient care. Of the 600 physicians originally identified, 537 were eligible. Of these, $344(64 \%)$ responded to the survey.

\section{Data collection}

Using computer assisted telephone interviews, we conducted a cross-sectional survey including both closed- and openended questions (questionnaire available upon request). ${ }^{20}$ Interviews were conducted between October 1999 and March 2000 by trained interviewers from the Center for Survey Research at the University of Massachusetts, Boston. The interviews took an average of 26 minutes to complete.

Participants were contacted by telephone and told about the study purpose and interview process. Participation was voluntary and did not involve the collection of personally identifiable information. This study was exempted from review by an institutional review board by the Office of Human Subjects Research at the National Institutes of Health.

All respondents were asked the following three openended questions:

- Can you describe a recent ethical dilemma you experienced at your main practice site?

- What do you consider to be the primary ethical issue or dilemma raised by the situation?

- Please briefly describe the decisions that were made as the situation played itself out.

The responses to these questions were entered into a database by the telephone interviewers during the interviews. Transcripts of responses may have left certain aspects of respondents' words aside, but these omissions are unlikely to have importantly affected the respondents' intended meaning. These responses were imported into QSR NUD*IST version N6 (QSR International, Victoria, Australia) qualitative research software to facilitate data analysis.

\section{Data analysis}

We adapted coding and analytical elements of grounded theory for this study..$^{21}{ }^{22}$ Although the structured approach to data collection would not allow for a formal grounded theory study, the size and richness of the dataset nonetheless made this approach likely to yield a useful range of inferences.

The first step involved examining the data, breaking them down, and making comparisons and conceptualisations, which were then labelled with a set of codes. Examples are given in table 1 . We initially broadly classified codes as "issues", "processes", and "values", and coded values as either "prioritised" or "not prioritised" according to whether they were fostered or undermined by the decision made.

\begin{tabular}{|cl|}
\hline Table 1 Examples of codes \\
\hline Issues & Incurable or dying patient disagreement \\
& Refusal of intervention \\
& Problematic proxy \\
Uncertainty & About the best goal \\
About decision-making capacity \\
Problematic requests \\
For futile treatment \\
For silence \\
For assisted death \\
Handling information \\
Communication \\
Confidentiality \\
Truth telling \\
Lack of knowledge/limits of medicine \\
Resource allocation \\
Intrusion of outsiders into decision making \\
Problems with colleagues \\
Conflict with rules or regulations \\
Conflict of interest \\
Refusal of intervention \\
Doing what is best \\
For the patient \\
For the family \\
Inclusiveness \\
Respect for the patient's self-determination \\
Respect for individuality \\
Patient advocacy \\
Defending life \\
Truth telling \\
To the patient \\
To the family \\
To others \\
Confidentiality \\
Duty to care for all \\
Avoid causing harm \\
Maintaining physician-patient relationship \\
Resource stewardship \\
Preventing abuse \\
Maintaining integrity \\
Compliance with rules and regulations \\
Maintaining collegiality \\
Protecting safety \\
Values \\
\\
\end{tabular}

In the second step, we reassembled the initial concepts into groups, or categories, according to relationships identified in the data, and broadened these categories to capture their different aspects and associations. For example, one participant said he had "agreed to buy time to allow the daughter to come around". Initially, this phrase was coded as an example of "waiting" (a "process" code). This was then seen to be one of several strategies used in "avoiding conflict", and this category was broadened to account for its different aspects such as the means used, the values fostered, the types of conflict avoidance, and the relationship to "looking for assistance".

In the final step, we identified the core category of "integrity". Although integrity is often used as a synonym for "honesty", it is used here in its broader sense of wholeness, acting in accordance with one's principles, and the integration of personality into a harmonious whole. ${ }^{23} 24$ "Looking for assistance" and "avoiding conflict" were seen as ways to protect the integrity of the group constituted by the decision makers, and of the respondent as a moral agent.

Two of the authors (SAH and $\mathrm{SCH}$ ) met regularly and double coded $10 \%$ of the dataset at various stages during the project to ensure that concepts were clearly defined and appropriately derived from the data, and that codes were being used consistently. Early data were recoded using the main concepts that emerged during later stages of the analysis.

In qualitative analysis, the appropriate sample size is reached when new data consistently fail to contribute new concepts or refinement to the emerging theory, a point in the 
analytical process known as "theoretical saturation". Since the questions were included in a survey administered to a random sample of physicians, we were not able to conduct additional interviews during the process of theory building. However, the dataset was rich enough to enable us to reach theoretical saturation for the main structural elements of the theory. ${ }^{25}$

For purposes of reading ease, quotes presented in this article have been completed from the telegraphic style in which transcripts were taken. Additions are identified by [ ]; where a part of the quote is left out, this is indicated by an ellipsis.

\section{RESULTS}

\section{Participants}

Respondents were predominantly male, Caucasian, and born in the USA (table 2). Their ages ranged from 26 to 79 years. The sociodemographic profile of respondents in the sample was parallel to that of US internists as a population. ${ }^{26}$ Of the respondents, 310 (90\%) could recall a recent ethical dilemma. There were no significant differences between the group of respondents who gave an ethics example and those who did not, with the exception of specialty. Critical care specialists recalled an ethical dilemma more often than either oncologists or general internists, and oncologists did so more often than general internists.

\section{Issues, persons, and values}

The first stage of the analysis included the identification of the issues most frequently reported by respondents, the persons most often mentioned as having been included in decisions, and the values most often recognised by respondents. We report the percentages of responses in which they are present as an indication of their salience in the dataset (table 3).

Situations in which the patient was not included in the discussion were primarily ones in which he or she was described as unconscious or incompetent, or when the main issue was resource allocation. In others, the issue was primarily with the family, as in cases where the problem was disagreement about what to tell the patient. There were also institutional issues that did not revolve around a particular patient, such as having to report illegal aliens, the implications of limitations to drug formularies, or hospital do not resuscitate policy.

When faced with situations they considered to be ethically difficult, the respondents looked for assistance and attempted to avoid conflict. Both were ways in which physicians tried to protect the integrity of their conscience and reputation, as well as the integrity of the group constituted by those who participated in the decisions.

\section{Looking for assistance}

When facing the ethical difficulties they described, most of the respondents looked for assistance. This could come from persons involved with the patient, or from persons trusted by the respondent for other reasons. At least six different reasons for looking for assistance were articulated:

- A need to obtain help in deciding what to do

- To identify a practical way of doing what had already been decided should be done

- To implement a practical solution

- To obtain reassurance that the correct decision was being made

- Better to face people who might otherwise think that the decision was inappropriate

- To seek consensus.
Table 2 Characteristics of the 310 respondents

\begin{tabular}{|c|c|}
\hline Characteristic & No. $(\%)^{*}$ \\
\hline \multicolumn{2}{|l|}{ Demographics } \\
\hline Male sex & $247(80)$ \\
\hline Female sex & $63(20)$ \\
\hline Median age (range $26-79$ years) & 40 \\
\hline \multicolumn{2}{|l|}{ Religion } \\
\hline Protestant & $88(29)$ \\
\hline Other Christian & 93 (31) \\
\hline Jewish & 43 (14) \\
\hline Muslim & $14(5)$ \\
\hline Hindu & $15(5)$ \\
\hline Buddhist & $4(1)$ \\
\hline Atheist/agnostic & $44(14)$ \\
\hline Other & $3(1)$ \\
\hline \multicolumn{2}{|l|}{ Ethnicity } \\
\hline Caucasian & $249(82)$ \\
\hline Of which: Hispanic & $21(7)$ \\
\hline African American & $8(3)$ \\
\hline Native American & $2(1)$ \\
\hline Asian & $42(14)$ \\
\hline Other & $4(1)$ \\
\hline \multicolumn{2}{|l|}{ Country of birth } \\
\hline USA & $206(67)$ \\
\hline Central or South America & $17(6)$ \\
\hline Europe & $19(6)$ \\
\hline Asia & $36(12)$ \\
\hline Africa & $5(2)$ \\
\hline Middle East & $18(6)$ \\
\hline Australia/New Zealand & $5(2)$ \\
\hline \multicolumn{2}{|l|}{ Ethics training } \\
\hline Median no. ethics rounds attended (range 0-500) & 8 \\
\hline Attended bioethics conference & $110(36)$ \\
\hline Ever ethics committee member & $68(22)$ \\
\hline \multicolumn{2}{|l|}{ Confidence about ethical standards } \\
\hline Very confident & $100(33)$ \\
\hline Moderately confident & $183(59)$ \\
\hline Not very confident & $23(7)$ \\
\hline Not at all confident & $3(1)$ \\
\hline $\begin{array}{l}\text { Access to an ethics consultation service, } \\
\text { at primary site or elsewhere }\end{array}$ & $258(83)$ \\
\hline \multicolumn{2}{|l|}{ Type of practice } \\
\hline Solo practice & $33(11)$ \\
\hline Single specialty group & 120 (39) \\
\hline Multi-specialty group & $73(24)$ \\
\hline University hospital/practice & 39 (13) \\
\hline Veterans Affairs/military & $8(3)$ \\
\hline Other hospital-based & $19(6)$ \\
\hline Resident or fellow & $13(4)$ \\
\hline Other & $5(2)$ \\
\hline Medical faculty appointment & $136(44)$ \\
\hline Median \% of managed care reimbursement & 30 \\
\hline (range 0-100) & \\
\hline \multicolumn{2}{|l|}{ Main admitting hospital } \\
\hline Public & $125(41)$ \\
\hline Private & $179(59)$ \\
\hline For profit & $54(18)$ \\
\hline Not for profit & $242(82)$ \\
\hline Median no. of patient beds (range 6-3450) & 400 \\
\hline \multicolumn{2}{|l|}{ No. of people in a 20 mile radius } \\
\hline$<50000$ & $21(7)$ \\
\hline $50000-100000$ & 39 (13) \\
\hline $100000-250000$ & 57 (19) \\
\hline $250000-500000$ & $44(14)$ \\
\hline$>500000$ & $147(48)$ \\
\hline Medical training & \\
\hline Critical care & $114(37)$ \\
\hline Internal medicine & $80(26)$ \\
\hline Oncology & $116(37)$ \\
\hline Entirely in the USA & $216(70)$ \\
\hline Partly in the USA & $84(27)$ \\
\hline Entirely abroad & 9 (3) \\
\hline MD subspecialty fellowship training & 244 (79) \\
\hline Additional degrees & $45(15)$ \\
\hline Master of Public Health & 8 \\
\hline Other Masters & 14 \\
\hline $\mathrm{PhD}$ & 21 \\
\hline Law & 1 \\
\hline Other & 1 \\
\hline Median total years in practice (range $2-57$ ) & 16 \\
\hline
\end{tabular}




\begin{tabular}{ll} 
Table 3 Issues, persons, and values ( $\mathrm{n}=310$ \\
respondents) & \\
\hline Most frequently identified issues* & $\%$ \\
\hline Incurable or dying patient & 65 \\
Disagreement & 54 \\
Problematic proxy & 39 \\
Uncertainty about the best goal & 27 \\
Requests for futile treatment & 24 \\
Allocation & 20 \\
Refusal of intervention & 19 \\
Lack of knowledge/limits of medicine & 13 \\
Communication & 10 \\
Persons mentioned as included & \\
Patient & 43 \\
Situations including others besides physician & 79 \\
and patient & \\
Family/proxy & 58 \\
Team & 18 \\
Colleagues & 15 \\
Administration involved & 7 \\
Payer involved & 6 \\
Ethics support consulted & 6 \\
Most frequently articulated values & \\
Doing what is best & 94 \\
For the patient & 92 \\
For the family & 9 \\
Inclusiveness & 61 \\
Respect for the patient's self-determination & 47 \\
Patient advocacy & 38 \\
Defending life & 38 \\
Avoiding causing harm & 28 \\
To the patient & 22 \\
To the family & 14 \\
Maintaining integrity & 22 \\
Resource stewardship & 12 \\
Telling the truth & 11 \\
Prioritised valuest & 76 \\
Inclusiveness & 69 \\
Patient advocacy & 55 \\
Respect for the patient's self-determination & 56 \\
Doing what is best for the patient & 52 \\
Avoiding causing harm to the patient & 30 \\
Defending life & \\
\hline & \\
\hline &
\end{tabular}

${ }^{*}$ Codes were not mutually exclusive.

†Percentages are the proportions of cases where these values were articulated by respondents.

One respondent gave this example of obtaining assistance to decide what to do:

[The problem was] release of confidential information in order to be employed and most patients are underemployed or unemployed and desperate for work. ... After consultation with [a] colleague and [a] lawyer [the decision was] to ask [the] patient to discuss [the] issue with [his] employer, and ... to contact me if any conflicts arise.

In the following case, assistance was obtained in finding a practical solution to transition from aggressive therapy to supportive care:

The patient became worse, progressive liver disease. Eventually the family was unwilling to have [a] discussion in front of [the] patient, believing she wouldn't want to know. Eventually the primary care physician [was] instrumental in coming to resolution for supportive care but not invasive intervention.

For some respondents the need for assistance to implement a solution to a difficult situation included, for example, "finding the resources that are available for a person to get drugs". One respondent reported the following case:
[The problem was] basically denial of payment by a third party for a needed life-sustaining service in a patient who could not afford it otherwise. Basically, when the HMO [health maintenance organisation] found out about the media coverage they began to be more interested in providing cover to the patient, plus with the help of the insurance consultant as well.

In some cases, the need for reassurance that a decision was deemed to be correct by others prompted the physician to request a second opinion, or to present the difficulty to a colleague for advice. In one respondent's words:

I had a patient whose partner, ... her live-in male companion, was a patient of my colleague and through my colleague I found out the partner was HIV positive. [The problem was] caring for my patient without breaching another doctor/patient confidence. ... All I could do was counsel her and my colleagues agreed that that was all I could do at the time.

Physicians also sought assistance in dealing with persons who might otherwise question the appropriateness of the decision being made. One respondent described an attempt to have a patient tell his wife that he wished life support to be withdrawn, so as to ensure that she did not question the team doing so:

He indicated he would not be removed from [the] vent when [his] wife was there, but when she was gone [he] expressed he wanted to come off [the] vent. ... The patient was felt to be competent but we needed him to state in front of his wife his wishes, so that there was no question that we had withdrawn life support without his desires being met ...

Finally, assistance led to consensus in some circumstances. Respondents reported "talking to different people ... for everyone to be comfortable". They "continued discussions with the family, back and forth" before making major decisions. They reported waiting for discussions to have led to agreement. In one example:

Despite the case being futile ... the patient continued to be supported, discussions were continued with various family members who were in disagreement among themselves. After an extended period of time the family came to [an] agreement that the patient's condition was terminal and elected to withdraw life support.

Assistance could decrease the moral burden of decision making for the respondent. When it was absent, this could be viewed as the main issue:

... the question was raised because of [there being] no family for guidance [on] what was the appropriate level of aggressiveness to go on with.

\section{Avoiding conflict}

The avoidance of conflict, between any parties, emerged as a goal in its own right. It often seemed to take priority over other goals. The approaches the respondents reported using to avoid conflict included putting in extra time and effort, and looking for assistance. Five different types of avoidance of conflict were present in the dataset: 
- Addressing a potential conflict before it crystallised

- Not facing a conflict

- Withdrawing from the case

- Detaching oneself from the potential conflict

- Acquiescing in order to eliminate a disagreement.

In the following case, conflict was avoided by addressing it before it crystallised. The respondent identified that a conflict could arise and worked to prevent it:

... it took more work for patient and family to realise his prognosis; ... [The problem was] how to get the message without affecting the physician/patient relationship. [The] outcome [was] that patient and family realised [the] terminal prognosis, so they agreed to change the level of care as was appropriate.

An example in which avoidance of conflict meant not facing it is illustrated in the following situation. In this case, deception was used: the respondent did what he thought was right, and pretended to the patient's family that he had done what they thought was right.

Despite prolonged discussions with [the] family, they had no clue; I chose to withhold treatment, passively allowing the patient to progress towards dying without discussing [this] with [the] family. They would not allow a [do not resuscitate] order, so I used a cosmetic code, so the family perceived we did everything we could do but we didn't. We went through some motions but they thought we did more.

Respondents also reported withdrawing from the case altogether, as in one situation where one "felt restricted and stepped out" and "the ultimate decision was to have [the] primary care doctor take over care", as "he felt comfortable with the decision".

Others detached themselves from the potential conflict:

I had a consult called for by [a] junior colleague ... I said [the] patient should be seen in hospital. [The] head of department never has time to see patients ... [He] had [the] patient seen in [the] outpatient department instead. [The] patient had [a] pulmonary embolism ... [The] consultant should have gone to see [the] patient in hospital despite [the] pain of being moved around ... It's because he was [a] high profile individual [and] had power ... I detached myself after I told my junior colleague, who had called me in, what should be done.

Finally, some acquiesced in order to eliminate a disagreement. This could sometimes involve transgressing the patient's wishes. In one case, the main issue was that "the patient's wishes were not pursued", since a ventilator was started against her/his wishes. However, "after 3 days the family finally decided that the patient was taken off the ventilator". In this case, initially going against the patient's wishes bought time for the patient's and the family's wishes to become aligned. Conflict was avoided and the patient's wishes were respected in the end.

Conflict was not always avoided. In the following case, another goal was seen as more important and conflict was instrumental in pursuing that other goal:

[The] lady didn't want surgery; [the] family did and wore her down to have surgery. She was clear. I let [the] family fight about it ... I thought [the] family was being reasonable. I let [the] family beat her up. ... It was a form of imposing the family and medical values ... [The] family [did the] dirty work.

As suggested by language in this response, even when it contributed to a resolution, conflict was viewed negatively.

\section{Integrity}

Looking for assistance and avoiding conflict both contributed to protecting, or attempting to protect, the integrity, or wholeness, of respondents' conscience and reputation, and the integrity of the group of individuals participating in the decision. This could mean integration of competing principles, holding true to commitments and standing up for one's judgement. In the dataset, integrity as wholeness also applies to groups, although in a more restricted sense. Protecting the integrity of the group in this sense means protecting its cohesiveness, its integration as an entity.

One respondent's struggle to integrate competing principles is apparent in the following example. In this case, the respondent reports the pull of two competing aspects of the situation, the need to adhere to the patient's wishes and the need to give her the best chance of surviving, and the attempt to salvage both:

[A] little old lady with [a] complex medical illness in intensive care unit [and on a] ventilator, wanted to have [the] ventilator discontinued and the family was struggling with it ... She developed an intercurrent problem. If treated [this] would have allowed her to survive; it was an invasive procedure. ... [The problem was] adhering to her wishes but offering her the best possibility of surviving and they seemed to be in conflict. We decided we would discontinue mechanical ventilation, but decided we would drain her pleural effusion. We didn't want her to die because she couldn't ... we wanted to offer the best chance of breathing after we pulled the tube out.

Integrity could also mean holding true to commitments. Respondents stated that "[the problem was] doing something against [their] belief" or that "the physician has to answer to the patient even when family members disagree and have unrealistic expectations".

It could also mean standing up for one's judgement. One respondent stated: "I was under pressure from nurses and the institution to withdraw care and I refused to do it".

The goals of protecting the integrity of the respondent's conscience, of her reputation, or of the group of individuals participating in the decision could seem incompatible with one another. When this happened, the respondents did not always assert their own views in resolving what to do:

There was terminal cancer and the patient acquired an infection, and the problem came up whether to pursue the question or just eliminate treatment of the infection and let the patient expire of septic shock or to treat it and let the patient die from lung cancer. The family demanded that no antibiotics or no liquid or food be given and the patient expired in 3 days. [The problem was] that a reversible condition could and should have been treated regardless of the prognosis of the terminal condition, which was malignancy, [but] we pulled all treatment and the patient expired.

Cases where protecting the integrity of the respondent's conscience and reputation were in tension could also be 
perceived as very difficult, as in the case where the team needed the patient to repeat "in front of his wife" his request that the ventilator be discontinued, "so that there was no question". In this case, an attempt to protect the respondent's reputation as well as the respondent's conscience may well have failed on both counts:

The conversation mostly consisted of his wife in tears saying she would die without him and she thought he would get better. I was blunt in my expression that she was focusing on her needs rather than her husband's. He indicated he did not want off the vent. I questioned him about his wishes of yesterday. We were not able to do it ... I said no more questions were to be asked of [the] patient because he could not make up his mind, he had us in a very untenable situation.

Protecting the integrity of the group could entail reluctance to accept input from those perceived as outsiders. One respondent stated: "I dug my heels not wanting to make medical decisions based on people extraneous to the actual decision making". Sometimes this could involve deciding who the group was, maybe in a manipulative way, apparently in order to make agreement more likely:

\section{Um ... first [decision] was mine, to bring issues up with the family. Second [was] to leave [the] patient out of [the] decision-making process. [The] third decision was to involve [the] family ... [and] to allow [the] family's expressed wishes to supersede those of the patient... [the] other decision is leaving nurses and other people out of the process.}

The need to preserve the integrity of the group of decision makers, obtain their support and assistance and avoid conflict sometimes took precedence over the prior wishes of an unconscious patient, or the pursuit of what was viewed as the patient's best interest:

We had [a] patient who was nearly brain dead, but for whom the family's religious convictions essentially required that we continue dialysis despite the presence of a living will to the contrary.

Families' wishes could matter very much, even when clearly in opposition to patients' wishes.

Conversely, in other examples, the need to protect both the respondent's conscience and the integrity of the group of individuals involved in the decision could foster respect for a patient's self-determination:

We decided that it is in the patient's best interest to have knowledge of what she has despite the family's concerns that she would "die faster" if she learned that she had an incurable disease. The info. was disclosed to the patient. The patient heard the options she had and made a decision based on knowing what she had and the potential risk and benefits of these options.

\section{DISCUSSION}

We have identified strategies that seem to play an important role in the practice of ethical decision making by physicians. These aspects have largely been overlooked in prior research on ethical decision making in medicine, which is based on truncated or hypothetical cases. In dealing with ethical difficulties, our respondents tried to obtain assistance, avoid conflict, and protect the integrity of their conscience and reputation, as well as the integrity of the group of individuals participating in the decision. Respondents were faced with several competing goals. They did not always successfully achieve them. Moreover, while the goals pursued were worthy ones, in some cases the means employed were not necessarily the most likely to achieve those aims, or to avoid moral problems along the way.

Since the sample included only general internists, oncologists, and critical care specialists, generalisations to other medical specialties should, of course, be made cautiously, as should generalisations to countries other than the USA. The sample also included a greater number of men than women, and more Caucasian than ethnic minority physicians. The size of the sample, however, meant that, despite this, we had a substantial number of examples from women and ethnic minority physicians. Thus, the respondent group largely included the gender and ethnic diversity that is present in American medicine. A further point is that the respondents were likely to have told us of the cases that had made most impression on them rather than the most frequent and representative ones, and to have simplified the cases by selecting the elements most striking to them in their accounts. Additionally, respondents can present only a single point of view regarding the dilemmas they describe. This last feature of the data collection along with the approach of letting them use their own concept of what "ethically difficult" meant, precludes any analysis of the ethical appropriateness of the actions that respondents took. This approach, however, is likely to give a better insight into the types of cases that trouble physicians, and the elements that are most salient to them when they perceive a case as ethically difficult. Focusing on the ethically difficult cases they identified and sought to resolve is necessary if we are to explore their strategies in doing this. Our inferences are plausible; they make sense, and fit with each other as well as with other findings both from the same dataset and from other published research.

The findings illustrate the central place held by attempts to protect integrity when facing ethical difficulties. They also illustrate the complexity of the concept of integrity, which is often used as a synonym for "honesty". However, its full meaning is more complex and includes wholeness, the integration of personality into a harmonious whole, holding steadfastly true to one's commitments, and regarding one's own judgement as one that should matter to others, as well as acting morally. ${ }^{23}$ It has been suggested that integrity could be a "cluster concept, tying together different, overlapping qualities of character under one term". ${ }^{23}$ The findings illustrate the presence of different aspects of this cluster in the practice of ethical problem solving in medicine.

The importance of avoiding conflict is prominent in the dataset. This, of course, does not make physicians unique. However, there is an expectation that physicians will make decisions based on their patients' health and interests, regardless of the risk of conflict they could face in doing so. The importance of avoiding conflict, although not entirely surprising, thus has particular consequences in this setting. Physicians may be avoiding conflict for practical reasons, since it can be an obstacle to coordinated action, but they may also be avoiding conflict for other reasons: for its own sake, because facing it requires skills that they sometimes lack, or because it requires resources they consider better spent elsewhere. It is conspicuous that the respondents extremely rarely mentioned concern about litigation. While exploring this will require further research, it highlights the need for skills in conflict prevention and resolution in medical practice. Skills in moral reasoning and in moral 
deliberation with others would also be useful in protecting integrity. Although ethics has been a part of most medical school curricula for some years, it does not always explicitly include these kinds of skills. ${ }^{27-30}$ Conflict prevention and resolution are usually completely absent from both clinical training and medical ethics curricula. Interpersonal skills such as interviewing are taught, but the focus is usually on obtaining and providing information, not negotiation or conflict prevention.

It is important that these findings also shed light on some reasons why physicians may prefer not to ask for an ethics consultation even in a situation they identify as ethically difficult. First, if physicians attempt to manage ethically difficult cases with the aim of avoiding conflict, they may not feel a need for outside help as long as they believe they can achieve this aim without it. The importance of conflict avoidance in the dataset also fits with other results from the same survey: conflict seems to be a trigger for ethics consultations. ${ }^{19}$ Ethics consultation appears to be perceived as a last resort rather than as the primary source of help in cases of ethical difficulty.

Secondly, even when seeking help, physicians may not be confident that an ethics consultation service would provide the right, or an effective, kind of assistance. Having an ethics consultant raise additional issues could seem more like a hindrance than a source of help. In the same survey, the types of assistance that physicians expected from ethics consultation overlapped only in part with what they reported seeking in the cases they described. ${ }^{31}$

Thirdly, protecting the integrity of the group of persons involved in the decisions sometimes led to exclusion of others from decision making. If ethics consultants are perceived as outsiders, this will reinforce any reluctance in seeking their help. This fits with one other study showing that physicians sometimes regard the use of an ethics committee as an intrusion into the physician-patient relationship, a loss of control, and an abdication of their responsibility. ${ }^{32}$ One way to overcome this difficulty would be to include ethics consultants earlier on, so that they would be a part of the group already when an ethical difficulty arises. This has been proposed elsewhere for other reasons. ${ }^{33}$ Findings from the present study suggest additional advantages to such a proactive approach.

Ethical difficulties are frequent in clinical practice and it is not necessarily feasible or desirable to have ethics consultants involved in all of them. However, in cases where their help would be useful, obstacles to involving them could become problematic.

Greater understanding of how physicians face ethical difficulties is crucial. The findings indicate that they use a range of strategies in these situations. Systematic assessment of the success of these strategies in reaching ethically acceptable outcomes will now be needed. One intriguing facet of these strategies was the interaction between the effort to avoid conflict and the effort to foster the integrity of the group of persons involved in the decision. In some cases, specific persons were explicitly excluded from the group of decision makers. It could be important to confirm whether this is an attempt to keep the group conflict free, and thus avoid a form of failure, by redefining the group to include only people among whom no conflict is likely. This question could merit further investigation. "Who gets to participate in this decision?" is certainly a question present in many ethically difficult cases. A choice to keep persons out of the process because they are likely to disagree, and for no other reason, would certainly be morally suspect. If such choices are being made by well intentioned people for apparently good reasons, such as avoiding conflict, addressing this issue specifically could be important.

\section{ACKNOWLEDGEMENTS}

The authors wish to thank James V Lavery, Fred Gill, Alex Rajczi, and the anonymous reviewers for their invaluable criticism of the manuscript, as well as Michael Ferry for technical help.

\section{Authors' affiliations}

S A Hurst, S C Hull, M Danis, Department of Clinical Bioethics, National Institutes of Health, Bethesda, MD, USA

G DuVal, University of Toronto Joint Centre for Bioethics, Toronto, ON, Canada

This study was funded by the National Institutes of Health. The views expressed here are the authors' own and do not reflect the position of the National Institutes of Health, of the Public Health Service, or of the Department of Health and Human Services.

SAH was supported by a grant from the Oltramare Foundation, Geneva, Switzerland, and by the University Hospitals of Geneva. The views expressed here are those of the authors and not necessarily those of the Oltramare Foundation or of the University Hospitals of Geneva.

\section{REFERENCES}

1 Lo B, Schroeder SA. Frequency of ethical dilemmas in a medical inpatient service. Arch Intern Med 1981;141:1062-4.

2 Bremberg S, Nilstun T. The variety of ethical issues in everyday practice. Interviews with Swedish GPs. Eur J Gen Pract 2001;7:143-7.

3 Andereck WS. Development of a hospital ethics committee: lessons from five years of case consultations. Camb Q Healthc Ethics 1992;1:41-50.

4 Brennan TA. Ethics committees and decisions to limit care. The experience at the Massachusetts General Hospital. JAMA 1988;260:803-7.

5 Simon A. Support for ethical dilemmas in individual cases: experiences from the Neu-Mariahilf Hospital in Gottingen. J Med Ethics 2001;27(Suppl 1): i18-20.

6 Reiter-Theil S. Ethics consultation on demand: concepts, practical experiences and a case study. J Med Ethics 2000;26:198-203.

7 Orr RD, Moon E. Effectiveness of an ethics consultation service. J Fam Pract 1993:36:49-53.

8 La Puma J, Stocking CB, Silverstein MD, et al. An ethics consultation service in a teaching hospital. Utilization and evaluation. JAMA 1988;260:808-11.

9 Frederick WC, Wasieleski D, Weber J. Values, ethics, and moral reasoning among healthcare professionals: a survey. HEC Forum 2000; 12:124-40.

10 Self DJ, Skeel JD, Jecker NS. A comparison of the moral reasoning of physicians and clinical medical ethicists. Acad Med 1993;68:852-5.

11 Braunack-Mayer A. Casuistry as bioethical method: an empirical perspective. Soc Sci Med 2001;53:71-81.

12 Kuhse H, Singer $P$, Rickard $M$, et al. Partial and impartial ethical reasoning in health care professionals. J Med Ethics 1997;23:226-32.

13 Norberg A, Udén G. Gender differences in moral reasoning among physicians, registered nurses and enrolled nurses engaged in geriatric and surgical care. Nurs Ethics 1995;2:233-42.

14 Rest JR, Narvaez D. Moral development in the professions. Hillsdale, NJ: Lawrence Erlbaum Associates, 1994.

15 Eastman JK, Eastman KL, Tolson MA. The relationship between ethical ideology and ethical behavior intentions: an exploratory look at physicians' responses to managed care dilemmas. J Bus Ethics 2001;31:209-24.

16 Hoffmaster CB, Stewart MA, Christie RJ. Ethical decision making by family doctors in Canada, Britain and the United States. Soc Sci Med 1991;33:647-53.

17 Bremberg S, Nilstun T. Patients' autonomy and medical benefit: ethical reasoning among GPs. Fam Pract 2000;17:124-8.

18 Holm S, Gjersoe P, Grode G, et al. Ethical reasoning in mixed nursephysician groups. J Med Ethics 1996;22:168-73.

19 DuVal G, Sartorius L, Clarridge B, et al. What triggers requests for ethics consultations? J Med Ethics 2001;27(Suppl 1):i24-9.

20 Harlow BL, Rosenthal JF, Ziegler RG. A comparison of computer-assisted and hard copy telephone interviewing. Am J Epidemiol 1985;122:335-40.

21 Miles M, Huberman A. Qualitative data analysis. Thousand Oaks, CA: SAGE, 1994.

22 Chandros Hull S, Taylor H, Kass NE. Qualitative methods. In: Sugarman J, Sulmasy DP, eds. Methods in medical ethics. Washington DC: Georgetown University Press, 2001:146-68.

23 Cox D, La Caze M, Levine M. Integrity. In: Zalta EN, eds. The Stanford encyclopedia of philosophy. Summer 2001 edition. http:// plato.stanford.edu/archives/sum2001/entries/integrity/ (accessed 20 Sept 2004).

24 Blackburn S. The Oxford dictionary of philosophy. Oxford: Oxford University Press, 1996:195.

25 Strauss A, Corbin C. Basics of qualitative research; techniques and procedures for developing grounded theory. Thousand Oaks, CA: SAGE, 1998.

26 American Medical Association. Physician characteristics and distribution in the US, 2000/2001. Chicago, IL: AMA, 2001 
27 Hope T, Fulford KW. The Oxford Practice Skills Project: teaching ethics, law and communication skills to clinical medical students. J Med Ethics 1994;20:229-34

28 Myser C, Kerridge IH, Mitchell KR. Teaching clinical ethics as a professional skill: bridging the gap between knowledge about ethics and its use in clinical practice. J Med Ethics 1995:21:97-103.

29 Smith SR, Balint JA, Krause KC, et al. Performance-based assessment of moral reasoning and ethical judgment among medical students. Acad Med 1994;69:381-6.
30 Way J, Back AL, Curtis JR. Withdrawing life support and resolution of conflict with families. BMJ 2002;325:1342-5

31 DuVal G, Clarridge B, Gensler G, et al. A national survey of US internists' experiences with ethical dilemmas and ethics consultation. J Gen Intern Med 2003;19:251-8

32 Davies L, Hudson LD. Why don't physicians use ethics consultation? J Clin Ethics 1999;10:116-25.

33 Danis $M$. The promise of proactive ethics consultation. Crit Care Med 1998;26:203-4.

\section{Clinical Evidence - Call for contributors}

Clinical Evidence is a regularly updated evidence-based journal available worldwide both as a paper version and on the internet. Clinical Evidence needs to recruit a number of new contributors. Contributors are healthcare professionals or epidemiologists with experience in evidence-based medicine and the ability to write in a concise and structured way.

Areas for which we are currently seeking authors:

- Child health: nocturnal enuresis

- Eye disorders: bacterial conjunctivitis

- Male health: prostate cancer (metastatic)

- Women's health: pre-menstrual syndrome; pyelonephritis in non-pregnant women However, we are always looking for others, so do not let this list discourage you.

Being a contributor involves:

- Selecting from a validated, screened search (performed by in-house Information Specialists) epidemiologically sound studies for inclusion.

- Documenting your decisions about which studies to include on an inclusion and exclusion form, which we keep on file.

- Writing the text to a highly structured template (about 1500-3000 words), using evidence from the final studies chosen, within 8-10 weeks of receiving the literature search.

- Working with Clinical Evidence editors to ensure that the final text meets epidemiological and style standards.

- Updating the text every six months using any new, sound evidence that becomes available. The Clinical Evidence in-house team will conduct the searches for contributors; your task is simply to filter out high quality studies and incorporate them in the existing text.

- To expand the topic to include a new question about once every 12-18 months.

If you would like to become a contributor for Clinical Evidence or require more information about what this involves please send your contact details and a copy of your CV, clearly stating the clinical area you are interested in, to Klara Brunnhuber (kbrunnhuber@ bmigroup.com).

\section{Call for peer reviewers}

Clinical Evidence also needs to recruit a number of new peer reviewers specifically with an interest in the clinical areas stated above, and also others related to general practice. Peer reviewers are healthcare professionals or epidemiologists with experience in evidence-based medicine. As a peer reviewer you would be asked for your views on the clinical relevance, validity, and accessibility of specific topics within the journal, and their usefulness to the intended audience (international generalists and healthcare professionals, possibly with limited statistical knowledge). Topics are usually 1500-3000 words in length and we would ask you to review between 2-5 topics per year. The peer review process takes place throughout the year, and our turnaround time for each review is ideally 10-14 days.

If you are interested in becoming a peer reviewer for Clinical Evidence, please complete the peer review questionnaire at www. clinicalevidence.com or contact Klara Brunnhuber (kbrunnhuber@bmjgroup.com). 